\title{
Deformation due to sliding of single and woven carbon tows in dry and epoxy-lubricated conditions
}

\author{
Olga Smerdova, Omar Benchekroun and Noel Brunetière \\ Olga Smerdova. Institut Pprime, CNRS, ISAE-ENSMA, Université de Poitiers, Futuroscope Chasseneuil F-86962, France \\ Corresponding author: olga.smerdova@ensma.fr \\ Omar Benchekroun. Institut Pprime, CNRS, ISAE-ENSMA, Université de Poitiers, Futuroscope Chasseneuil F-86962, France \\ Present address: Ecole Centrale de Casablanca, Bouskoura, Ville Verte, 27182, Maroc
}

Noel Brunetière. Institut Pprime, CNRS, ISAE-ENSMA, Université de Poitiers, Futuroscope Chasseneuil F-86962, France

\begin{abstract}
This experimental work focuses on the evaluation of deformation mechanisms due to sliding between carbon fiber tows with a flat tool in dry and lubricated with liquid resin conditions. The experiments were carried out on manually woven and single tows. The effect of angle between tow axes and sliding direction was also studied. The topography of the tows in contact with a sliding transparent glass plate was measured with a 3D optical microscope before and after sliding. These measurements revealed a decrease of roughness with sliding in all tested conditions, a contraction of lubricated single tows in perpendicular to sliding orientation, and high residual displacements in lubricated woven tows in $0^{\circ} / 90^{\circ}$ orientation and dry single tows in perpendicular to sliding orientation.
\end{abstract}

Keywords. Carbon Tow, Friction, Sliding, Lubrication, Forming

\section{Introduction}

In manufacturing of woven composites, i.e. in the resin transfer molding process, dry tows are woven and compressed with a tool to shape them in a preform, which is then impregnated with liquid resin and solidified by curing. During this process, there are numerous occasions for tows to slide either in dry or lubricated by resin state. Local heterogeneity in tow sliding can result in defects of composite part and should be avoided if possible.

Several research groups have studied friction mechanism of single tows in mesoscopic [1-3] and microscopic scale [4-6] and woven materials in macroscopic scale [7-10]. The effect of orientation on the friction forces was quantified and discussed [11-13]. The lubricated by resin friction was studied on macroscopic fabrics [7-10, 14]. However, nor lubrication effect on friction of single tows neither evolution of tows' surface due to sliding were evaluated. The aim of this work is to identify deformation mechanisms that affect friction in tow/tool sliding. A relation between friction and surface deformation of lubricated and dry single tows in transversal orientation was subject of a separate publication [15].

\section{Materials and Experimental method}

Several series of experiments were carried out on carbon fiber tows T700SC-12k-60E taken out of a spool. These fibers have an average diameter of $6.7 \mu \mathrm{m}$ and a small amount of sizing to enhance the compatibility with epoxy. Around 12,000 fibres are aligned in a tow and maintained together only by adhesion forces. The resin used to lubricate the tow was EpoFix epoxy resin by Struers used without hardener. The viscosity given by the manufacturer was $600-800 \mathrm{cP}$ at $25^{\circ} \mathrm{C}$. A small amount of epoxy was poured into the sliding area such as it does not touch the sticky tape or clamping plates and compromise the fixation. The tests on woven tows and single tow in parallel orientation were repeated once, while the tests on a single tow in perpendicular to sliding orientation were repeated 4 times in reciprocated sliding tests and seven times in incremental sliding tests.

The surface of the tow under sliding contact with glass plate was observed with Alicona Infinite Focus optical 
Deformation due to sliding of single and woven carbon tows in dry and epoxy-lubricated ...

microscope. This microscope measures 3D surface topography by creating stacks of images in multiple vertical positions. The images are then analysed by the microscope software and the vertical position of each pixel is determined by its best focus with respect to neighbouring pixels. The transparency of glass was used to observe the tow surface under contact before and after sliding. In lubricated by liquid epoxy experiments, a correction coefficient of 1.6 due to different refraction index of the medium was determined on a reference surface and applied to all measured tow surfaces. All measurements presented in this study were performed at a magnification objective of $x 5$, which gave a lateral resolution of $3.457 \mu \mathrm{m}$ per pixel and a vertical resolution of $0.41 \mu \mathrm{m}$.

\subsection{Experimental setup for sliding of woven tows}

Firstly, the tows were woven manually and fixed by a sticky tape at their ends to the acrylic bottom plate, such as schematized in Fig. 1(a). By this technique, a fabric of 4 by 4 tows was created. A lead frame with a glass window was put onto the surface of the fabric such as four middle tow junctions were clearly visible through the window and far from the edges of the frame. The weight of the frame applied the compression load of $1.8 \mathrm{~N}$ onto the fabric. The surface of the fabric was firstly measured right after compression. The frame was then pushed by a micrometric screw through a known distance and the surface was measured again. The arrangement of this experiment is presented in Fig 2(a). The orientation of tows with respect to sliding distance was defined by the angle $\alpha$, as shown in Fig 1(a). The experiments were carried out in $0^{\circ}, 30^{\circ}$ and $45^{\circ}$ orientation in both lubricated and sliding conditions.

\subsection{Experimental setup for sliding of single tows}

For the second series of measurements, a new rig was designed and assembled with the aim to study friction and surface deformation of a single tow. The rig, presented in Fig. 2(b), can apply lubricated and dry sliding between a carbon tow and a glass plate as in the first experiment. The glass plate of $17.5 \times 17.5 \mathrm{~mm}^{2}$ was framed into an aluminum part pushed by a micrometric screw through a load cell. The tension/compression cell from Futek of load capacity of $+/-8.89 \mathrm{~N}$ measured the friction force due to sliding of the glass on the tow. A thin elastic beam was mounted between the load cell and the micrometric screw to enable small vertical compensations due to change of tow thickness during sliding. The rigidity of the setup in the orientation of sliding was high with respect to the contact rigidity, so the measured force was attributed solely to friction. The friction measurements are not presented in this paper, but they are being published in a separate journal article [15]. The normal load of $6.8 \mathrm{~N}$ was applied onto the contact through a suspended mass. The tow was clamped by two plates at both ends with $90 \mathrm{~mm}$ between them. An axial pretension of $5 \mathrm{~N}$ was applied to the tows before clamping. A second glass plate was placed under the central area of the tow and covered with a silicon paper with visible color texture. The experiments were carried out in parallel and perpendicular to sliding orientation, as schematized in Figs 1(b) and 1(c). The surface of the tow in contact with glass was measured before sliding and then after each $1 \mathrm{~mm}$ of sliding up to $3 \mathrm{~mm}$ of total sliding distance. 
(a)

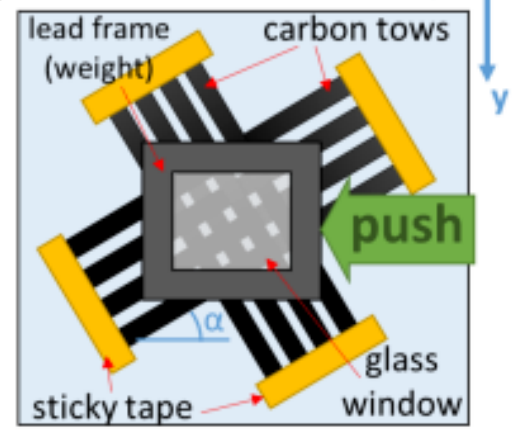

(b) Al frame with weight suspended beneath the table

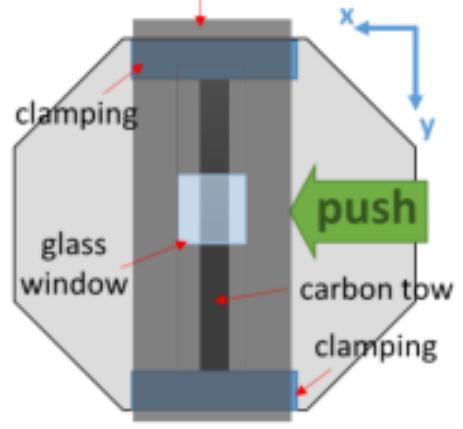

(c) Al frame with weight suspended beneath the table

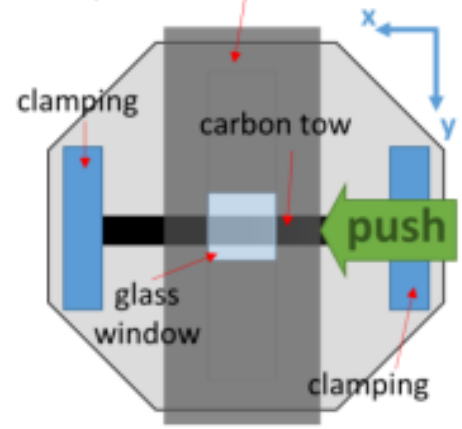

Fig. 1. Geometry of sliding arrangements.

(a) woven tows, (b) single tow in perpendicular to sliding orientation and (c) single tow in parallel to sliding orientation.

(a)

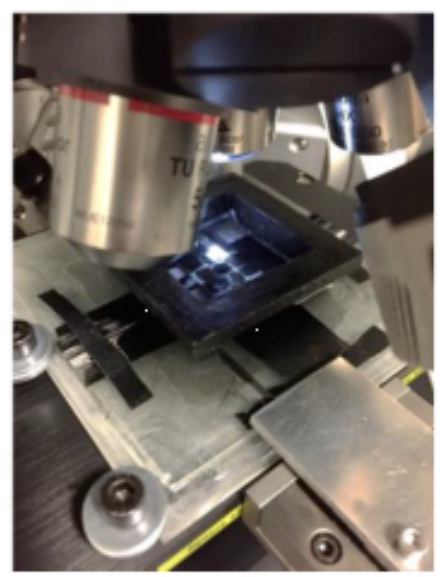

(b)

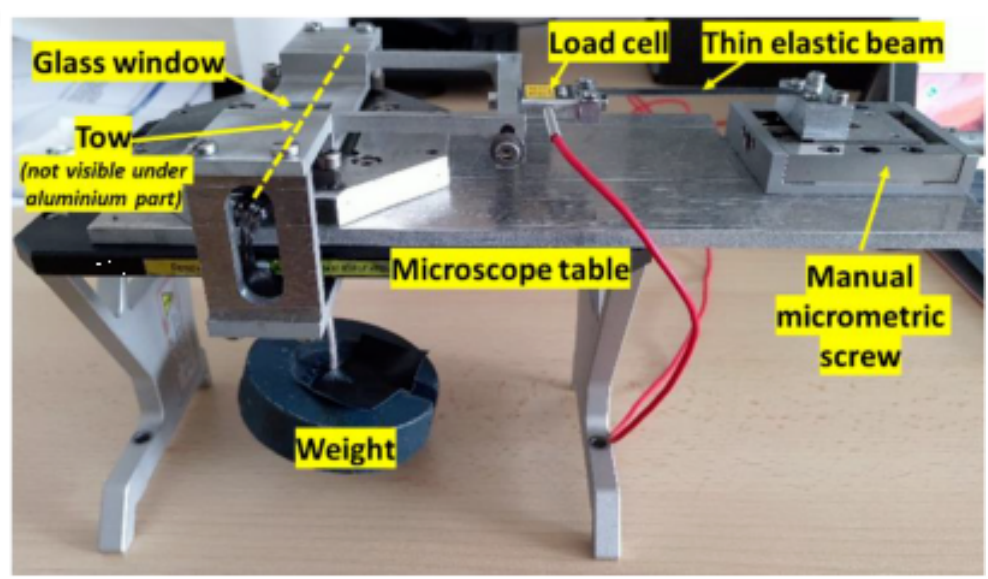

Fig. 2. Experimental setups for woven and single tows sliding experiments.

(a) Woven tows under the microscope and (b) the rig to be placed under the microscope for the single tow sliding experiments

\subsection{Analysis of the experimental data}

The examples of measured surfaces are presented in Fig. 3 for woven tows and a single tow under transversal sliding. For both cases, an image before sliding and one after $3 \mathrm{~mm}$ of sliding are given. Each image of woven tows is leveled on the whole measured area and then analyzed with Gwyddion software. For the four tow junctions entirely visible in the area, a rectangular area is selected such as the left top and the right bottom corners are at the intersections of two tow edges (see red rectangular in Fig. 3). The centroid of this rectangular is considered as current position of the junction in $\mathrm{X}$-Y plane. Since the measurement area was similar for all displacement increments, the displacement of each junction was calculated as a difference between the current and the initial coordinates of the centroid as specified in the Fig. 3. 
Deformation due to sliding of single and woven carbon tows in dry and epoxy-lubricated ...

$$
\begin{aligned}
& u_{x i}=x_{i}-x_{0} \\
& u_{y i}=y_{i}-y_{0}
\end{aligned}
$$

where $\left(x_{0}, y_{0}\right)$ are the centroid coordinates before sliding and $\left(x_{i}, y_{i}\right)$ are those at the current sliding increment $i$. The direction $\mathrm{x}$ coincided with the sliding direction in all experiments.

The roughness of the top area of each junction was calculated on a smaller rectangular, represented in gray color in Fig.3. This area of around half area of the junction was chosen manually. Then, the arithmetic average roughness parameter $R_{a}$ was calculated by the software as follows

$$
R_{a}=\frac{1}{n} \sum\left|z_{i}\right|
$$

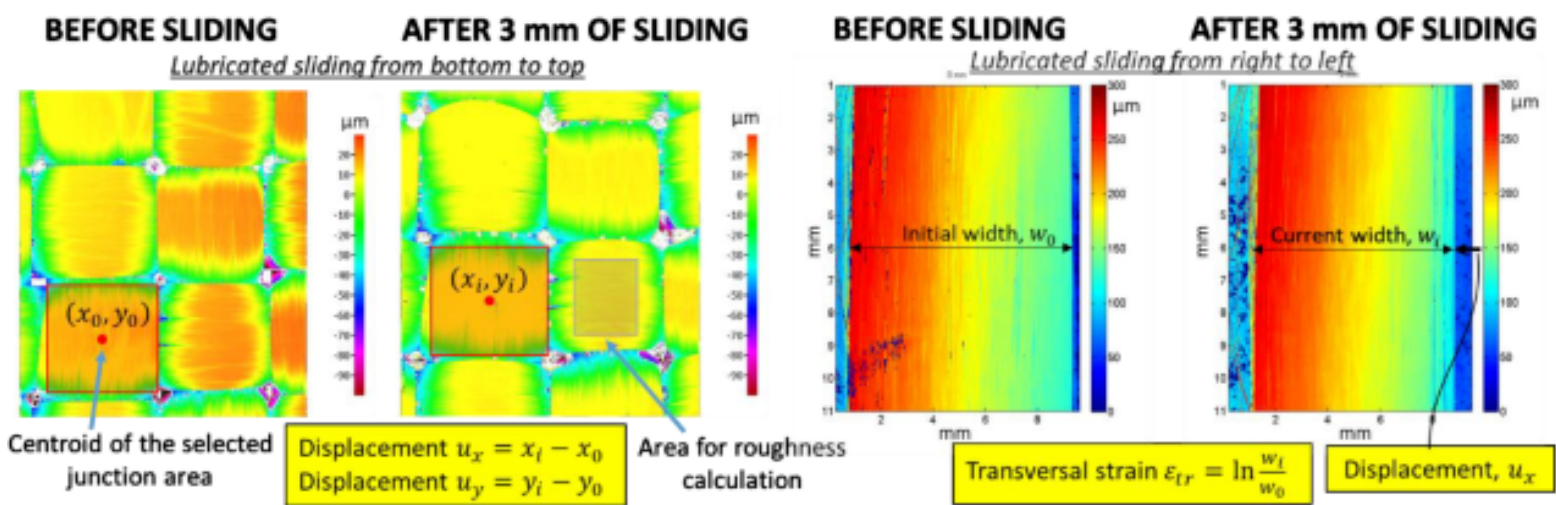

Fig. 3. Surface topographies measured on $4 \times 4$ woven tows and a single tow before and after $3 \mathrm{~mm}$ of sliding in lubricated conditions. The direction of sliding and the determined parameters are indicated on the figure.

The parameters determined from a single tow experiment in perpendicular orientation are shown on the right-hand side of Fig.3. The algorithm was similar for tows sliding in parallel orientation with the image rotated by $90^{\circ}$ before the analysis. The surface of the single tow was levelled with respect to the bottom surface. Its edges were detected through an image processing algorithm written in Matlab based on a gradient method. The 3D data was then averaged perpendicularly to tow axis orientation on the length of $3.5 \mathrm{~mm}$ to obtain a single profile. The width of this profile is considered as a tow width $w$ and used to calculate the logarithmic transversal strain $\varepsilon$ tr as follows

$$
\varepsilon_{t r}=\ln \frac{w_{i}}{w_{0}}
$$

The displacement of the tow is defined through the change of the right edge x-coordinate of the profile similarly to Eq. 1a. The roughness of the tow close to the contact was determined in a more accurate and elaborate way. Since the 
alignment between two plates was not perfect, a small angle of the order of $1^{\circ}$ was observed for the top glass plate. The most probable position of a plane representative of the glass surface was found through a Matlab algorithm of minimization of the distance between the profile and this plane $\mathrm{d}$. The average gap was then calculated on the whole profile as follows

$$
\bar{d}=\frac{\sum d \times w_{p}}{w}
$$

where $w_{p}$ is the pixel width. This parameter represents the roughness of the tow with respect to the contact plane.

\section{Results and discussions}

\subsection{Sliding of woven tows}

An example of measured surface of a lubricated fabric oriented in $0^{\circ}$ to sliding direction is presented in Fig. 3. Since a bottom plate is covered in these tests, an absolute thickness of the tows is not possible to measure. The measurements provide relative position of the top surface of the fabric with respect to its middle plane. Nevertheless, the areas of tow junctions are seen to protrude from the surface. The color of all junctions is not the same demonstrating that either the glass plate was inclined, or the contact was not established on all bumps. Indeed, it is rather difficult to determine from these measurements where the contact actually took place. However, an analysis of surface profiles allowed us to conclude that some junctions were not in contact since they were not flattened by compression and their vertical positions were inferior to their neighbors. Their vertical position is governed by the axial tension in each tow, which is applied by hand in our experiments. Nevertheless, Fig. 3 demonstrates a clear difference between the surface before and after sliding.

The displacements and roughness measurements calculated by the procedure presented above and averaged between four tow junctions at each sliding step in every orientation are presented in Fig. 4. In the initial state after compression, the dry fabric is rougher than the lubricated one by around $7 \mu \mathrm{m}$ in average roughness. The drop of roughness after sliding is significant in dry condition for $0^{\circ}$ and $30^{\circ}$ orientation, but rather small in other conditions. The rougher surface in $45^{\circ}$ might be explained by difficulties in manual fixation of the tows in this orientation. Smoother surfaces in lubricated conditions are due to the compression step, in which the lubrication favorizes sliding and rearrangements between fibers. These movements under compression are more restricted in dry conditions, but they are induced by shear forces created by sliding of the glass. This is supported by the observed smoothening of the surface in dry condition.

The tow displacements after $3 \mathrm{~mm}$ of sliding in dry conditions are rather limited, as shown in Fig. $4 \mathrm{~b}$. This must be due to prevalence of internal sliding and fiber rearrangements. Lubricated tows slide greatly in $0^{\circ}$ orientation (the example presented in Fig.3), but not significantly in other orientations. Their displacement is parallel to sliding orientation without any movement or contraction in perpendicular orientation. The reason for this mobility might be due to a lower bending stiffness of internally lubricated tows. The measurements reveal rather complex mechanisms. While some of upper tow areas stick to the glass surface and change their X-Y position because of the glass sliding, at the same time they slide onto the tows underneath and induce movement and deformation of neighbor tows due to their own deformations. The great deformability and displacements of tows in $90^{\circ}$ to sliding orientation required proper study to identify relevant mechanisms. That is why, the sliding experiments on a single tow presented below were conducted. 

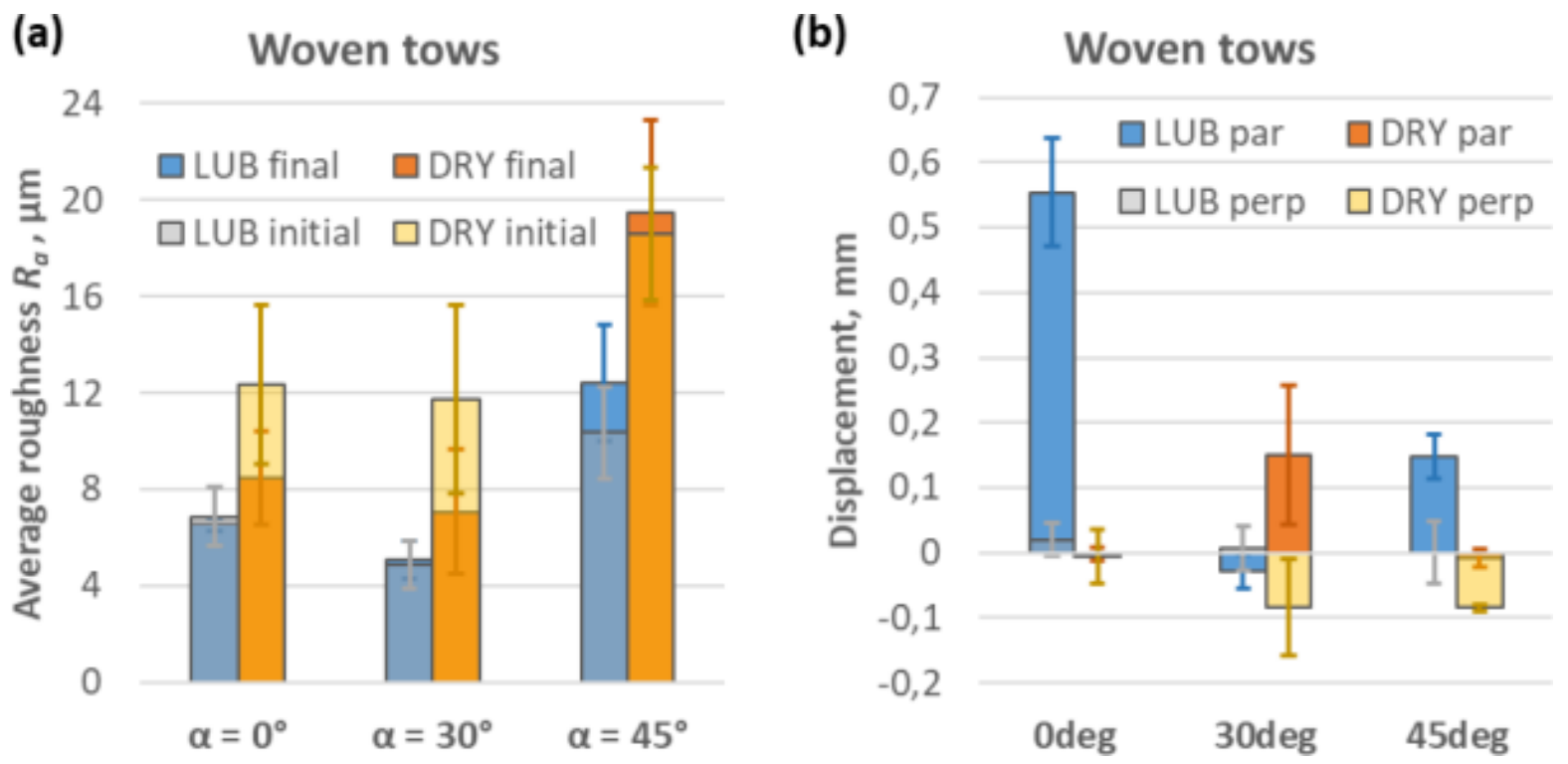

Fig. 4. Average roughness and displacement of woven tows in $0^{\circ}, 30^{\circ}$ and $45^{\circ}$ to tow axes orientation.

(a) Roughness at the top of tow junctions and (b) displacement of tow junctions in parallel and perpendicular to sliding direction

\subsection{Sliding of single tows in parallel and perpendicular orientation}

The results of single tow sliding tests are presented in Fig. 5. Firstly, the surface of the tows seems to smooth slightly with sliding distance for all conditions, as on can see in Fig. 5(a) by decrease of the roughness parameter d, the average distance between the glass and carbon fibers. This parameter is of the same order of magnitude as the average roughness $R_{a}$, presented in Fig. 4(a) but it is less dependent on the position of the mean plane and the selected area. Moreover, the dispersion between the results in perpendicular orientation decreases with sliding suggesting that all the tows tend to similar smoother state in lubricated and dry conditions.

The residual displacement measured after sliding in perpendicular to fiber axis orientation by three increments of 1 mm is presented in Fig. 5(b). Indeed, the tow being rather compliant in transversal orientation, it slides significantly despite both ends clamped. This must be due to imperfect fiber alignment and uneven distribution of axial pretension between fibers that left the room to movements. This figure shows that the residual displacement increases with sliding steps and is higher in dry condition. Since the imaging is performed after the sliding stops, the measured displacement might be not representative of the one during sliding. It is likely that the tows slide back after the stop, and this effect is higher for lubricated tows due to viscosity of the epoxy. These results are inverse to the displacement measured on woven tows (see Fig. 4(b)) highest for lubricated condition. The reason must be in the restrictions of movement imposed by neighbor tows in woven configuration, which are absent in the long single tow. 

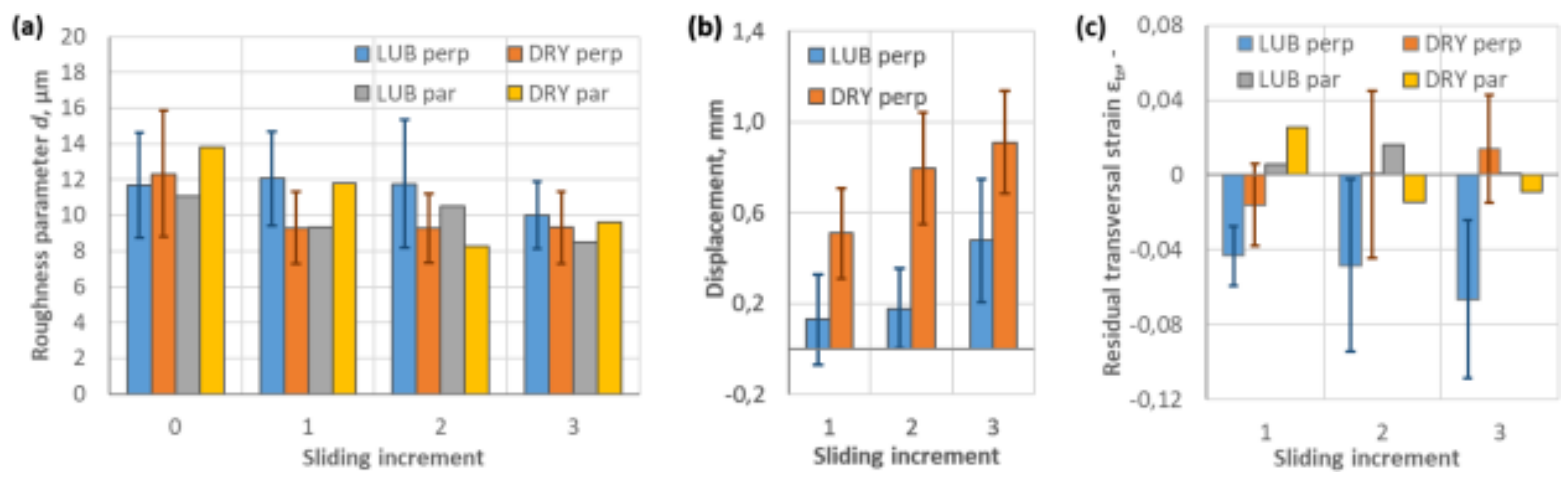

Fig. 5. Deformation and displacement under sliding of single tows in parallel and perpendicular to tow axis orientation.

(a) average distance from glass surface $d$, (b) displacement of tow due to sliding in perpendicular orientation and (c) Residual transversal strain of tows $\varepsilon_{t r}$.

Finally, a change of tow width due to sliding was quantified both in perpendicular and parallel orientation and is presented in Fig. 5(c). A contraction of the lubricated tows in perpendicular to sliding orientation is observed up to $10 \%$ in some cases. For other conditions, this effect is rather limited and remains under $2-3 \%$ on average. It would be interesting to compare with the behavior of fabric, but the comparison is not obvious since the deformation is not even when the tows are woven (see Fig. 3).

\section{Conclusions}

The objective of this experimental work was to identify deformation mechanisms of single and woven tows under sliding against a tool in dry and lubricated by liquid resin conditions. In particular, the effect of sliding on surface roughness and on the displacement of tows were studied. The first parameter can in theory be related to the friction force due to its effects on the real contact area and bearing capacity of the tow. The second parameter is particularly interesting since it describes the appearance of defects in composite parts during forming processes.

The experiments revealed that the roughness of tow surface decreased with sliding when they were woven and single with and without lubricant. The effect of sliding on the displacement was opposite between fabric and single tows: while woven lubricated tows slid significantly and dry remained in place, the single tow in perpendicular to sliding orientation slid more in dry condition. This result must be taken with prudence since the displacements are residual after the stop of sliding. It would be interesting to repeat the experiment with in-situ observations during sliding. Nevertheless, these tests provide an evaluation of tow shear rigidity under sliding with and without epoxy, which might be useful for simulations of forming processes.

\section{Acknowledgements}

The authors are very grateful to Prof. Michael Sutcliffe from the University of Cambridge, for useful discussions throughout this work and for supplying the carbon tows. This work was partially funded by the Institut Pprime ACI programme and pertains to the French government program "Investissements d'Avenir" (LABEX INTERACTIFS, reference ANR-11-LABX-0017-01 and EUR INTREE, reference ANR-18-EURE-0010). Pprime Institute gratefully acknowledges "Contrat de Plan Etat - Région Nouvelle- Aquitaine" (CPER) as well as the "Fonds Européen de Développement Régional (FEDER)" for their financial support to the reported work. 
Deformation due to sliding of single and woven carbon tows in dry and epoxy-lubricated ...

\section{Bibliography}

[1] Tourlonias, M. Bueno, M-A. Poquillon, D. Friction of carbon tows and fine single fibres. Compos A Appl Sci Manuf 2017;98:116-123.

[2] Cornelissen, B. Rietman, B. Akkerman, R. Frictional behaviour of high performance fibrous tows: Friction experiments. Compos A Appl Sci Manuf 2013;44:95- 104.

[3] Mulvihill, D.M. Sutcliffe, M.P.F. Effect of tool surface topography on friction with carbon fibre tows for composite fabric forming. Compos A Appl Sci Manuf 2017;93:199-206.

[4] Smerdova, O. Sutcliffe, M.P.F. Novel experimental method for microscale contact analysis in composite fabric forming. Exp Mech 2015;55(8):1475-83.

[5] Smerdova, O. Sutcliffe, M.P.F. Multiscale tool-fabric contact observation and analysis for composite fabric forming. Compos A Appl Sci Manuf 2015;73:116-24.

[6] Mulvihill, D.M. Smerdova, O. Sutcliffe, M.P.F. Friction of carbon fibre tows. Composites 2017; 93:185-198.

[7] Fetfatsidis, K.A. Jauffrès, D. Sherwood, J.A. Chen, J. Characterization of the tool/fabric and fabric/fabric friction for woven-fabric composites during the thermostamping process. Int J Mater Form 2013;6:209-221. DOI 10.1007/ s12289-011-1072-5

[8] Lin, H. Harrison, P. van de Haar, K. Long, A.C. Akkerman, R. Clifford, M.J. Investigation of tool-ply friction of viscous textile composites. In: Proc TEXCOMP- 8, 2006.

[9] Murtagh, A.M. Monaghan, M.R. Mallon, P.J. Investigation of the interply slip process in continuous fibre thermoplastic composites. In: Proc 9th ICCM Conf, 1993.

[10] Sach, U. et al. Characterization of the dynamic friction of woven fabrics: Experimental methods and benchmark results. Compos A Appl Sci Manuf 2014;67:289- 298.

[11] Chakladar, N.D. Mandal, P. Potluri, P. Effects of inter-tow angle and tow size on carbon fibre friction. Compos A Appl Sci Manuf 2014;65:115-24.

[12] Tourlonias, M. Bueno, M.-A. Fassi, G. Aktas, I. Wielhorski, Y. Influence of friction angle between carbon single fibres and tows: Experimental analysis and analytical model. Compos 2019;124:105478.

[13] Dackweiler, M. Hagemann, L. Coutandin, S. Fleischer, J. Experimental investigation of frictional behavior in a filament winding process for joining fiber-reinforced profiles. Compos Struct 2019;229:111436.

[14] Ten Thije, R.H.W. Akkerman, R. Ubbink, M. van der Meer, L. A lubrication approach to friction in thermoplastic composites forming processes. Compos A Appl Sci Manuf 2011;42:950-960.

[15] Smerdova, O. Benchekroun, O. Brunetiere, N. Transversal friction of epoxy-lubricated and dry carbon tows: From initial stages to stabilised state. Compos A Appl Sci Manuf 2021;143:106263.

PDF automatically generated on 2021-05-20 08:20:19

Article url: https://popups.uliege.be/esaform21/index.php?id=3981

published by ULiège Library in Open Access under the terms and conditions of the CC-BY License 
ESAFORM 2021. MS01 (Friction \& Wear), 10.25518/esaform21.3981

(https://creativecommons.org/licenses/by/4.0) 